\title{
The Influence of Nd and Sm on the Structure and Properties of Sol-Gel-Derived $\mathrm{TiO}_{2}$ Powders
}

\author{
Albena Bachvarova-Nedelcheva ${ }^{1, *}$, Stancho Yordanov ${ }^{2}$, Reni Iordanova ${ }^{1}$, Irina Stambolova ${ }^{1}$, \\ Angelina Stoyanova ${ }^{3}$, Nelly Georgieva ${ }^{4}$ and Veronica Nemska ${ }^{4}$ (D)
}

check for

updates

Citation: Bachvarova-Nedelcheva,

A.; Yordanov, S.; Iordanova, R.;

Stambolova, I.; Stoyanova, A.;

Georgieva, N.; Nemska, V. The

Influence of $\mathrm{Nd}$ and $\mathrm{Sm}$ on the

Structure and Properties of

Sol-Gel-Derived $\mathrm{TiO}_{2}$ Powders.

Molecules 2021, 26, 3824.

https://doi.org/10.3390/

molecules26133824

Academic Editor: Stoyan Gutzov

Received: 27 May 2021

Accepted: 20 June 2021

Published: 23 June 2021

Publisher's Note: MDPI stays neutral with regard to jurisdictional claims in published maps and institutional affiliations.

Copyright: (C) 2021 by the authors. Licensee MDPI, Basel, Switzerland. This article is an open access article distributed under the terms and conditions of the Creative Commons Attribution (CC BY) license (https:/ / creativecommons.org/licenses/by/ $4.0 /)$.
1 Institute of General and Inorganic Chemistry, Bulgarian Academy of Sciences, Acad. G. Bonchev str., bld. 11, 1113 Sofia, Bulgaria; reni@svr.igic.bas.bg (R.I.); irinast@svr.igic.bas.bg (I.S.)

2 Institute of Metal Science, Equipment and Technologies "Acad. A. Balevski" with Center for Hydro- and Aerodynamics at the Bulgarian Academy of Sciences, 67 Shipchenski prohod str., 1574 Sofia, Bulgaria; stancho14@abv.bg

3 Department Chemistry and Biochemistry, Faculty of Pharmacy, Medical University—Pleven, K1. Ohridski str., 1, 5800 Pleven, Bulgaria; astoy@abv.bg

4 Department Biotechnology, Faculty of Chemical and Systems Engineering, University of Chemical Technology and Metallurgy, Kl. Ohridski Blvd, 8, 1756 Sofia, Bulgaria; nelly.georgieva@yahoo.com (N.G.); vnemska@uctm.edu (V.N.)

* Correspondence: albenadb@svr.igic.bas.bg

\begin{abstract}
TiO}_{2}$ nanopowders modified by $\mathrm{Nd}$ and $\mathrm{Sm}$ were prepared using the sol-gel technique. It was found by XRD analysis that the samples containing Sm are amorphous up to $300{ }^{\circ} \mathrm{C}$, while those with $\mathrm{Nd}$ preserve a mixed organic-inorganic amorphous structure at higher temperatures $\left(400{ }^{\circ} \mathrm{C}\right)$. The $\mathrm{TiO}_{2}$ (rutile) was not detected up to $700{ }^{\circ} \mathrm{C}$ in the presence of both modified oxides. $\mathrm{TiO}_{2}$ (anatase) crystals found at about $400{ }^{\circ} \mathrm{C}$ in the Sm-modified sample exhibited an average crystallite size of about $25-30 \mathrm{~nm}$, while doping with $\mathrm{Nd}$ resulted in particles of a lower size- $-5-10 \mathrm{~nm}$. It was established by DTA that organic decomposition is accompanied by significant weight loss occurring in the temperature range $240-350{ }^{\circ} \mathrm{C}$. Photocatalytic tests showed that the samples heated at $500{ }^{\circ} \mathrm{C}$ possess photocatalytic activity under UV irradiation toward Malachite green organic dye. Selected compositions exhibited good antimicrobial activity against E. coli $\mathrm{K} 12$ and B. subtilis.
\end{abstract}

Keywords: sol-gel; powders; thermal stability; X-ray diffraction

\section{Introduction}

Titanium dioxide $\left(\mathrm{TiO}_{2}\right)$ remains one of the most promising materials for various applications such as self-cleaning, gas sensors, catalytic performance, and environmentally friendly photocatalyst [1-3]. Due to its high optical transparency, thermal stability, nontoxicity, chemical inertness, and environmentally friendly nature it is the preferred oxide [1,2]. However, its application in a visible light range of the solar spectrum is limited due to the wide band gap energy $(3.2 \mathrm{eV})$ and in order to increase catalytic efficiency, stability and light absorption, it should be modified by doping of metals. Recent review papers reported additional progress towards the efficient application of this promising material in water and wastewater treatment under visible light [4,5]. In recent years, modification with some rare earth (RE) metals has proven to be an efficient method of improving the photocatalytic properties of $\mathrm{TiO}_{2}$ and broadening its absorption within the solar spectrum [3,6,7]. Moreover, it was found that the presence of RE ions slowed down the rate of the charge-carrier recombination processes [6].

According to published literature, RE-modified $\mathrm{TiO}_{2}$ can be prepared by a wide spectrum of methods, such as sol-gel [6,8], hydrothermal [9], solvothermal [10], electrospinning [11], co-precipitation [12], and electrochemical [13]. It is reported that from all the above methods, sol-gel has the greatest possibility of homogeneous distribution of dopant in the host material with a large surface area of $\mathrm{TiO}_{2}$ particles. Some authors found 
that combining hydrothermal treatments with the sol-gel method provided an alternative approach for preparing $\mathrm{TiO}_{2}$ thus preventing the agglomeration of the nanocrystals [14]. It was also established that the synthesis method significantly affects the structural, optical, luminescence and photocatalytic properties. At present, it has been established that $\mathrm{TiO}_{2}$ modified with $\mathrm{Y}^{3+}, \mathrm{Pr}^{3+}, \mathrm{Er}^{3+}$, and $\mathrm{Eu}^{3+}$ obtained through the hydrothermal method approach exhibited a higher photocatalytic activity, while the samples prepared via the sol-gel method approach yielded more luminescence when irradiated with $980 \mathrm{~nm}$ photons [15].

The rare earth elements such as neodymium $(\mathrm{Nd})$, holmium $(\mathrm{Ho})$, cerium $(\mathrm{Ce})$, gadolinium (Gd) have been also used for doping $\mathrm{TiO}_{2}$ and these studies have been summarized by Daghrir [16]. The neodymium $\left(\mathrm{Nd}^{3+}\right)$ ions are well known for improving photocatalytic activity by decreasing the energy band gap due to the transfer of charge between the $\mathrm{TiO}_{2}$ valence/conduction band and the $4 \mathrm{f}$ level in rare earth ions $[15,16]$.

However, Sm-doped $\mathrm{TiO}_{2}$ has been also investigated [17-21]. Most of the studies concluded that $\mathrm{Sm}^{3+}$ ions increase the surface area but also enhance the photocatalytic activity under UV or solar light irradiation [18]. With reference to organic dyes, it was established that the presence of Sm is highly effective against Rhodamine B and Methyl orange with an optimal doping concentration of $0.5 \%$ [22-24].

It is well known that titanium dioxide $\left(\mathrm{TiO}_{2}\right)$ has been extensively studied also with reference to antibacterial applications. Although several $\mathrm{TiO}_{2}$ nanocomposites with antimicrobial capabilities have been reported, they exhibit poor antibacterial activity in the visible light region due to the large band gap of $\mathrm{TiO}_{2}(3.2 \mathrm{eV})$ [25]. Some new approaches established that the rare earth doping of $\mathrm{TiO}_{2}$ resulted in antibacterial activities in the visible light region [26-28]. Relatively few papers [22,25] reported on the antibacterial performance of $\mathrm{Nd}-\mathrm{TiO}_{2}$ and $\mathrm{Sm}-\mathrm{TiO}_{2}$ nanopowders but additionally modified by coating with Ag.

In our previous papers, we presented experimental studies concerning sol-gel synthesis of binary and multicomponent composite powders with good photocatalytic and antibacterial properties [29-33]. Our studies on modification with some lanthanides ( $\mathrm{La}^{3+}$, $\left(\mathrm{Ce}^{3+}\right), \mathrm{TiO}_{2}$ showed that doping with rare metals sometimes improved the photocatalytic activity under UV irradiation and was not beneficial under Vis irradiation [34-36]. On the basis of the accumulated knowledge, we continue extensive studies on the modified $\mathrm{TiO}_{2}$ powders investigating their thermal, optical, and structural properties. Our priority is to research new combinations from compositions containing $\mathrm{TiO}_{2}$, especially those that have not been investigated until now.

To our knowledge, a comparison of the sol-gel-derived $\mathrm{TiO}_{2}$ powders modified with $\mathrm{Nd}^{5+}$ and $\mathrm{Sm}^{3+}$ has not been reported until now. Hence, the focus of the present work is to pay more attention to the synthesis as well as the structural, optical, photocatalytic activities, and antibacterial properties of the obtained powdered samples. The properties of as-prepared samples were compared with pure $\mathrm{TiO}_{2}$ as well.

\section{Results and Discussion}

\subsection{Phase Transformations}

All gels prepared at room temperature were transparent as the modified with $\mathrm{Sm}$ and $\mathrm{Nd}$ exhibited identical bright orange color and their visual observations are shown in Figure 1.
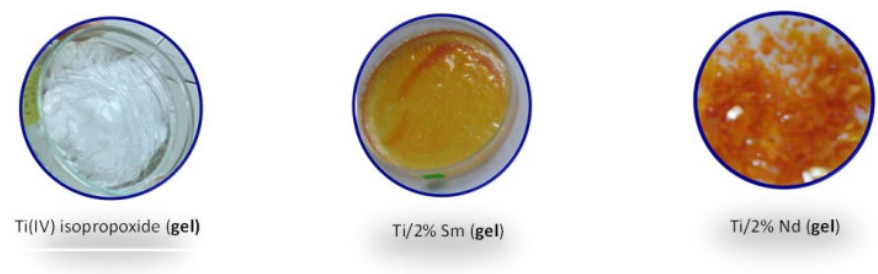

Figure 1. Images of the as-prepared gels. 
Bearing in mind the strong complexation processes occurred after the addition of acetylacetonate during the sol-gel processes it could be suggested that the observed color is due to the simultaneous presence of chelating agent and the rare eart ions $\mathrm{Sm}^{3+}$ and $\mathrm{Nd}^{3+}$.

The XRD patterns of the gels and the heat-treated samples in the temperature range of $200{ }^{\circ} \mathrm{C}-700{ }^{\circ} \mathrm{C}$ are shown in Figure 2. The XRD patterns of the precursors used (TTIP and TTIP/i-PrOH) were presented for comparison, as well (Figure 3). As can be seen from Figure 2, both samples preserve the amorphous state up to $300{ }^{\circ} \mathrm{C}$ but the TN sample containing $2 \% \mathrm{Nd}$ is amorphous even at $400{ }^{\circ} \mathrm{C}$. Obviously, doping with $\mathrm{Nd}$ suppresses the earlier crystallization of $\mathrm{TiO}_{2}$ (anatase). Increasing the calcination temperature leads to the appearance of the first diffraction peaks at $2 \Theta=25.3,38.4$ and 48.1 corresponding to $\mathrm{TiO}_{2}$ (anatase) (JCPDS 78-2486). There is an absence of peak at $2 \Theta=27.4$, which corresponds to $\mathrm{TiO}_{2}$ (rutile), which indicates that anatase is the only crystalline phase detected in the temperature range of $500-700{ }^{\circ} \mathrm{C}$ in both samples. It is worth noting that the phase transition $\mathrm{TiO}_{2}$ (anatase)- $\mathrm{TiO}_{2}$ (rutile) did not occur in the investigated samples (Figure 2) and both rare earth ions hinder this transformation. No characteristic peaks for $\mathrm{Nd}$ and $\mathrm{Sm}$ are observed in the modified samples, indicating that these ions do not substitute $\mathrm{Ti}^{4+}$ in the crystal lattices, which can be attributed to the difference in the radii of $\mathrm{Ti}^{4+}(0.53 \AA), \mathrm{Nd}^{3+}$ $(0.99 \AA)$ and $\mathrm{Sm}^{+3}(0.96 \AA)$ [37,38]. Similar results have been obtained by Bokare et al. [25] which have suggested that possibly $\mathrm{Nd}$ and $\mathrm{Sm}$ exist in the form of $\mathrm{Nd}_{2} \mathrm{O}_{3}$ and $\mathrm{Sm}_{2} \mathrm{O}_{3}$ small particles, uniformly dispersed between the $\mathrm{TiO}_{2}$ nanocrystallite or deposited on the surface of $\mathrm{TiO}_{2}$ nanoparticles. From Figure 2, it can be also seen that at $500{ }^{\circ} \mathrm{C}$, the main diffraction peak of anatase phase is broad and this indicated that the samples have a small particle size.
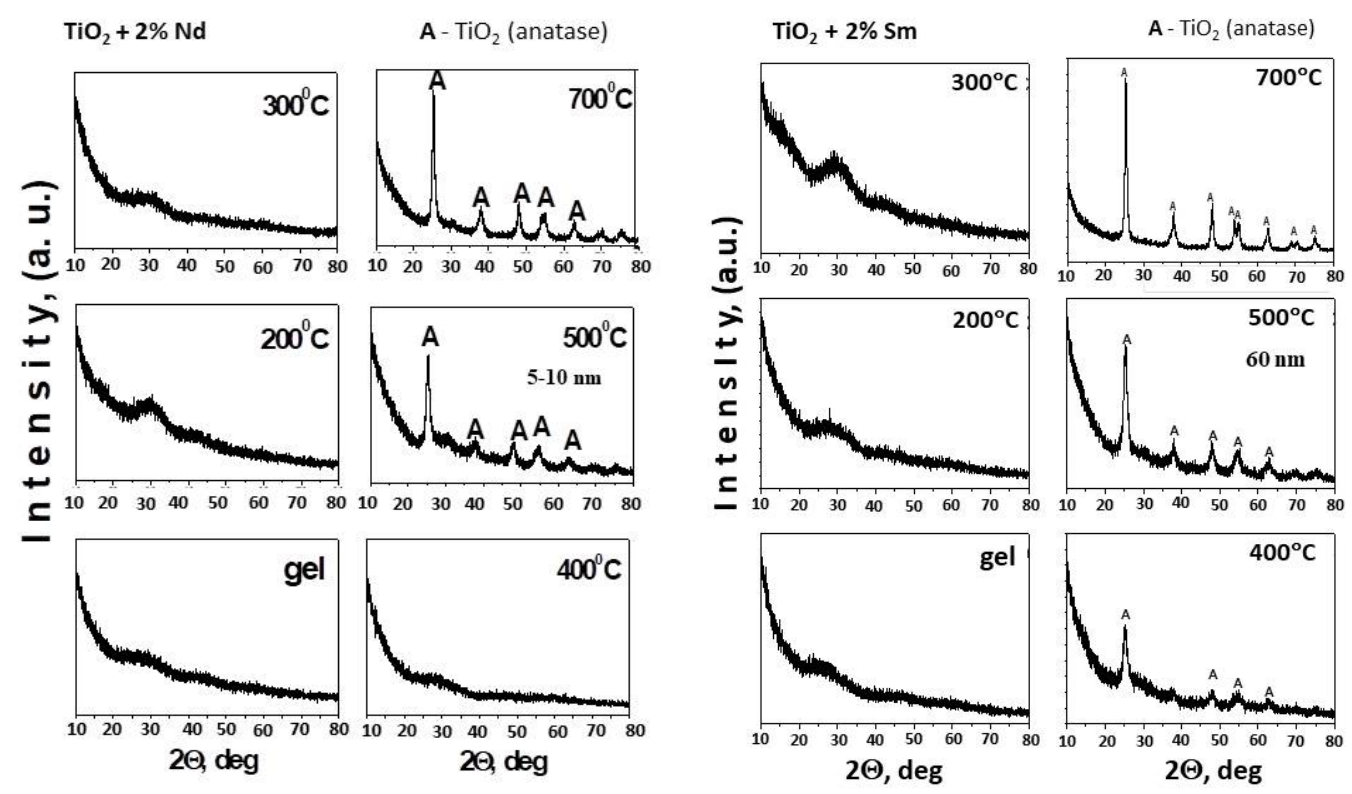

Figure 2. XRD patterns of $\mathrm{TiO}_{2}$ modified with $2 \% \mathrm{Nd}$ and $2 \% \mathrm{Sm}$ heat-treated at different temperatures: $(\mathrm{A}) \mathrm{TiO}_{2}$-anatase. 

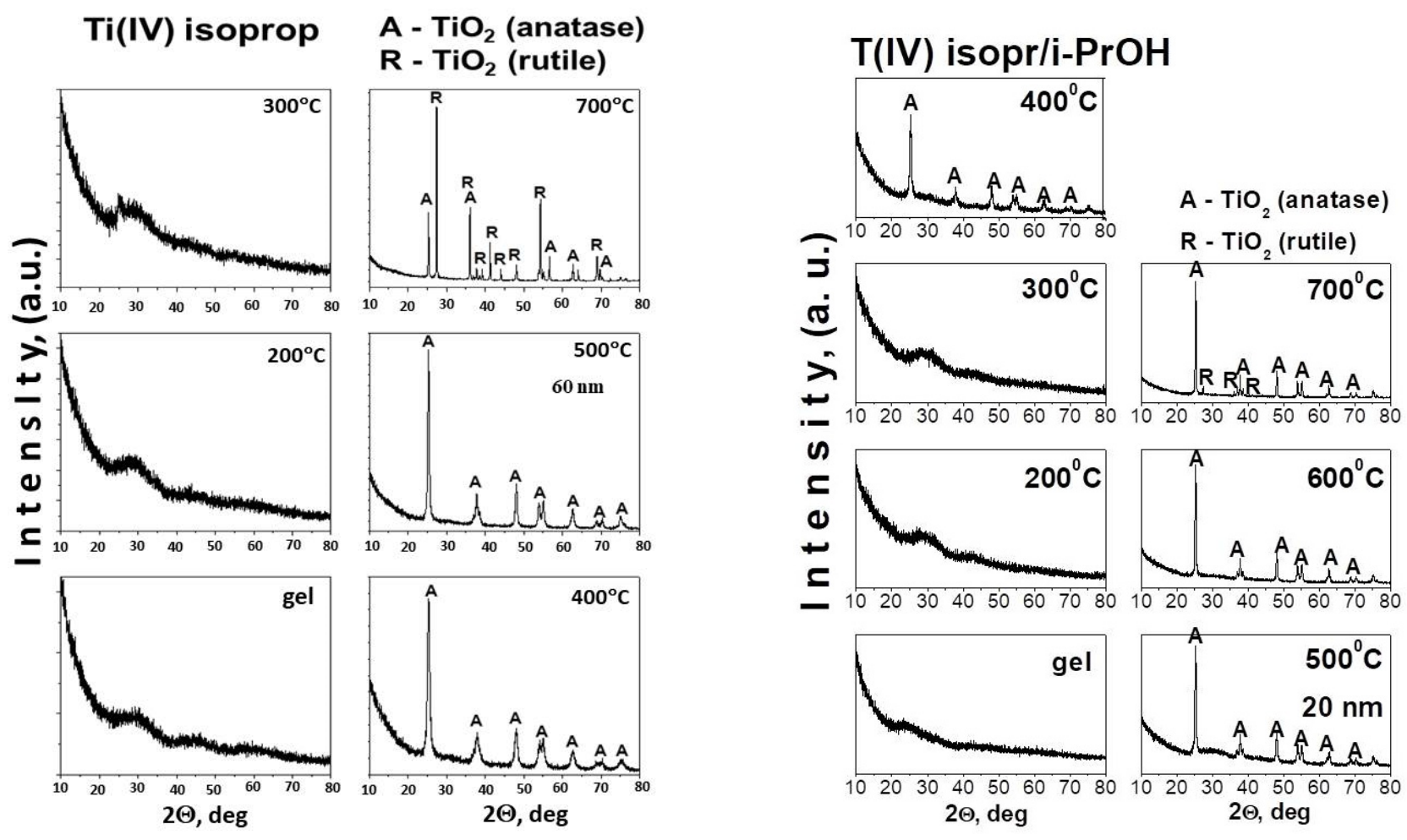

Figure 3. XRD patterns of used precursor Ti(IV) isopropoxide (TTIP) and TTIP dissolved in i-PrOH: (A) $\mathrm{TiO}_{2}$-anatase, (R) $\mathrm{TiO}_{2}$-rutile.

Looking at the XRD pattern of the pure TTIP and TTIP/i-PrOH (Figure 3), it could be seen that both undoped samples up to $300{ }^{\circ} \mathrm{C}$ exhibited similar behavior to TN and TS samples, but the difference is that the first $\mathrm{TiO}_{2}$ (anatase) crystals appeared at $400{ }^{\circ} \mathrm{C}$ while at $700{ }^{\circ} \mathrm{C}, \mathrm{TiO}_{2}$ (rutile) was registered.

At $500{ }^{\circ} \mathrm{C}$, the average crystallite size (calculated using the Sherrer's equation, based on the strongest peak) of $\mathrm{TiO}_{2}$ (anatase) for sample TN is about $5-10 \mathrm{~nm}$, while for the TS one it is about $60 \mathrm{~nm}$ (Figure 2). In comparison, at this temperature, the average crystallite size of $\mathrm{TiO}_{2}$ (anatase) is about $20 \mathrm{~nm}$ (Figure 3) in the undoped TTIP and TTIP + $\mathrm{i}-\mathrm{PrOH}$ samples. Obviously, the $\mathrm{Nd}$ dopant preserves the smaller $\mathrm{TiO}_{2}$ (anatase) particles size dimensions. This refers to that the doping ions $\left(\mathrm{Nd}^{3+}\right)$ retard the grain growth of $\mathrm{TiO}_{2}$ nanoparticles and similar results of decreasing crystalline nature of material were observed by several authors [22,25].

Our results concerning the calcination temperature effect on the phase formation concur with those reported in the literature [3,39-41]. The specific surface areas (SBET) of samples TN and TS were measured, and they are 118 and $81 \mathrm{~m}^{2} / \mathrm{g}$, respectively. In comparison, the specific surface area of pure $\mathrm{TiO}_{2}$ obtained by the $\mathrm{Ti}(\mathrm{IV})$ isopropoxide is $21 \mathrm{~m}^{2} / \mathrm{g}$. This higher value of the specific surface area for both samples could predict potential good environmental applications.

\subsection{Thermal Stability of the Gels}

The thermal stability of gels aged at room temperature was investigated by simultaneous thermogravimetric (TG) and differential thermal analysis (DTA). DTA/TG curves of the used precursors are not presented but it has been studied and discussed elsewhere [42-44]. The DTA/TG curves are presented for both gels-TN (TTIP-2\%Nd) and TS (TTIP-2\% Sm) (Figure 4) and several stages could be marked on them. The DTA curves of both samples showed similar behaviour. As is seen from figure one of the common features is a stepwise release of the organics probably as a result of the higher number of organic groups due to the presence of solvent and chelating agent as well. The first decomposition step of the 
gels is a weak endothermic effect near $100{ }^{\circ} \mathrm{C}$ (Figure 4a-d). This step could be attributed to the evaporation of physically adsorbed water and/or organic solvent (isopropanol). The average mass loss after dehydration is about $10 \%$ for both samples. The first exothermic peak is at about $245^{\circ} \mathrm{C}$ and it could be related to the combustion of alkoxide groups bonded to Ti-atom. That peak is accompanied by the mass loss of $10 \%$ for the TN gel, while for the TS sample this value is higher ( 16.5\%). The next exothermic effect in both samples is at about $350{ }^{\circ} \mathrm{C}$ and it could be assigned to the combustion of residual organic groups but in the TS sample, it may be connected to the beginning of the $\mathrm{TiO}_{2}$ (anatase) crystallization as well. The mass loss at this stage is about $17 \%$ for the TN sample and $\sim 10 \%$ for the TS one. As is seen there is a difference in the thermal behavior of the investigated samples above $500{ }^{\circ} \mathrm{C}$. The comparison of the DTA-TG curves of the samples showed that one exothermic effect at about $580^{\circ} \mathrm{C}$ is observed in the TN gel while in the other one, three consecutive exothermic effects were detected (at $520^{\circ} \mathrm{C}, 545^{\circ} \mathrm{C}$, and $570{ }^{\circ} \mathrm{C}$ ). It is also obvious that in both cases, a mass loss of an average of $10 \%$ is observed. Obviously, in the presence of samarium, the last decomposition is more gradual in comparison to the other sample. On the basis of these experimental facts, it could be assumed that the effects in the range $520-540{ }^{\circ} \mathrm{C}$ in the TS sample could be related to the oxidation of residual carbon and release of $\mathrm{CO}_{2}$. The last exothermic effects at $570{ }^{\circ} \mathrm{C}$ (for TS) and $580{ }^{\circ} \mathrm{C}$ (for TN) could be associated with the intensive crystallization of anatase for both cases (Figure 4). The results obtained by DTA correspond well to the XRD data (Figure 2), as well as to the results obtained by other authors for $\mathrm{Nd}$ and $\mathrm{Sm}$-modified $\mathrm{TiO}_{2}$ powders $[43,45,46]$.
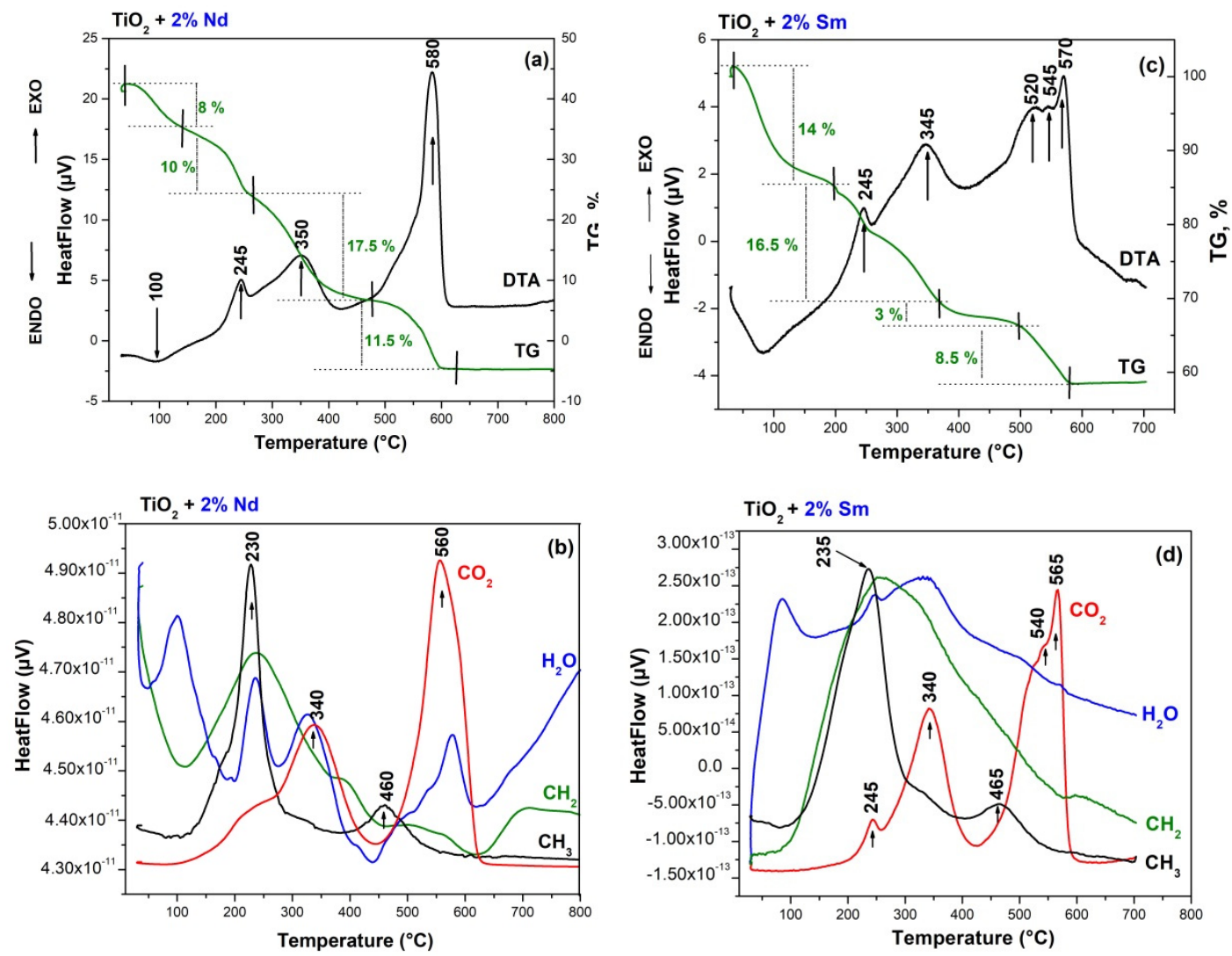

Figure 4. Differential thermal analysis (DTA)/thermogravimetric (TG) curves of the TN) (a,b) and TS (c,d) samples.

\subsection{Structural Studies and Optical Properties}

The IR spectroscopy was used not only for verifying the phase transformations occurring with heat treatment (in the temperature range $200-500^{\circ} \mathrm{C}$ ) but also to evaluate the rate and degree of hydrolysis and condensation processes. The IR spectra of investigated samples are depicted in Figure 5. The vibrational spectra of pure Ti(IV) isopropoxide 
(TTIP) as well as of isopropanol were shown and discussed already elsewhere [42,47]. By analogy with our previous papers, the assignments of the vibrational bands of separate structural units are made on the basis of well-known spectral data for TTIP, isopropanol and crystalline $\mathrm{TiO}_{2}$ (anatase) [42,47]. Looking at Figure 5, it is seen that intensive bands are observed in the IR spectra of the gels, but their intensities decreased with the temperature increasing. Moreover, it is obvious that there is a similarity regarding the position and intensity of the bands for the heat-treated samples in the range $200-500{ }^{\circ} \mathrm{C}$. A decrease in the intensity of organic groups is registered after heating in the range $200-300{ }^{\circ} \mathrm{C}$. These groups disappeared completely above $300^{\circ} \mathrm{C}$. Generally, the bands located between $1500-1300 \mathrm{~cm}^{-1}$ are assigned to the bending vibrations of $\mathrm{CH}_{3}$ and $\mathrm{CH}_{2}$ groups. The band at $1120 \mathrm{~cm}^{-1}$ is characteristic for the stretching vibrations of Ti-O-C, while those at 1190 and $1020 \mathrm{~cm}^{-1}$ are assigned to the vibrations of terminal and bridging $\mathrm{C}-\mathrm{O}$ bonds in alkoxy ligands [47]. The absorption bands below $1000 \mathrm{~cm}^{-1}$ in the samples correspond to C-H, C-O and deformation Ti-O-C vibrations [48,49]. In our previous investigations [50,51], it was found that the absorption region $1100-1020 \mathrm{~cm}^{-1}$ is very complex due to the overlapping of the vibrations of different structural units from the alkoxide and solvent. Inspite of that, many authors [52-54] use these bands for the interpretation of the degree of hydrolysiscondensation processes. Bearing in mind the similarity of the spectra of investigated samples, it is difficult to evaluate the completeness of the hydrolysis-condensation reactions. However, the absence of a weak band at about $1120 \mathrm{~cm}^{-1}$ in the IR spectra of TS gel gives us reason to suggest that more completed hydrolysis reactions occurred in that sample. The bands below $800 \mathrm{~cm}^{-1}$ correspond to the vibrations of $\mathrm{TiO}_{6}$ units $[52,53]$. Bearing in mind that the typical Sm-O and $\mathrm{Nd}-\mathrm{O}$ stretching vibrations are in the range of $510-430 \mathrm{~cm}^{-1}[55,56]$ overlapping between the inorganic structural polyhedra is suggested.
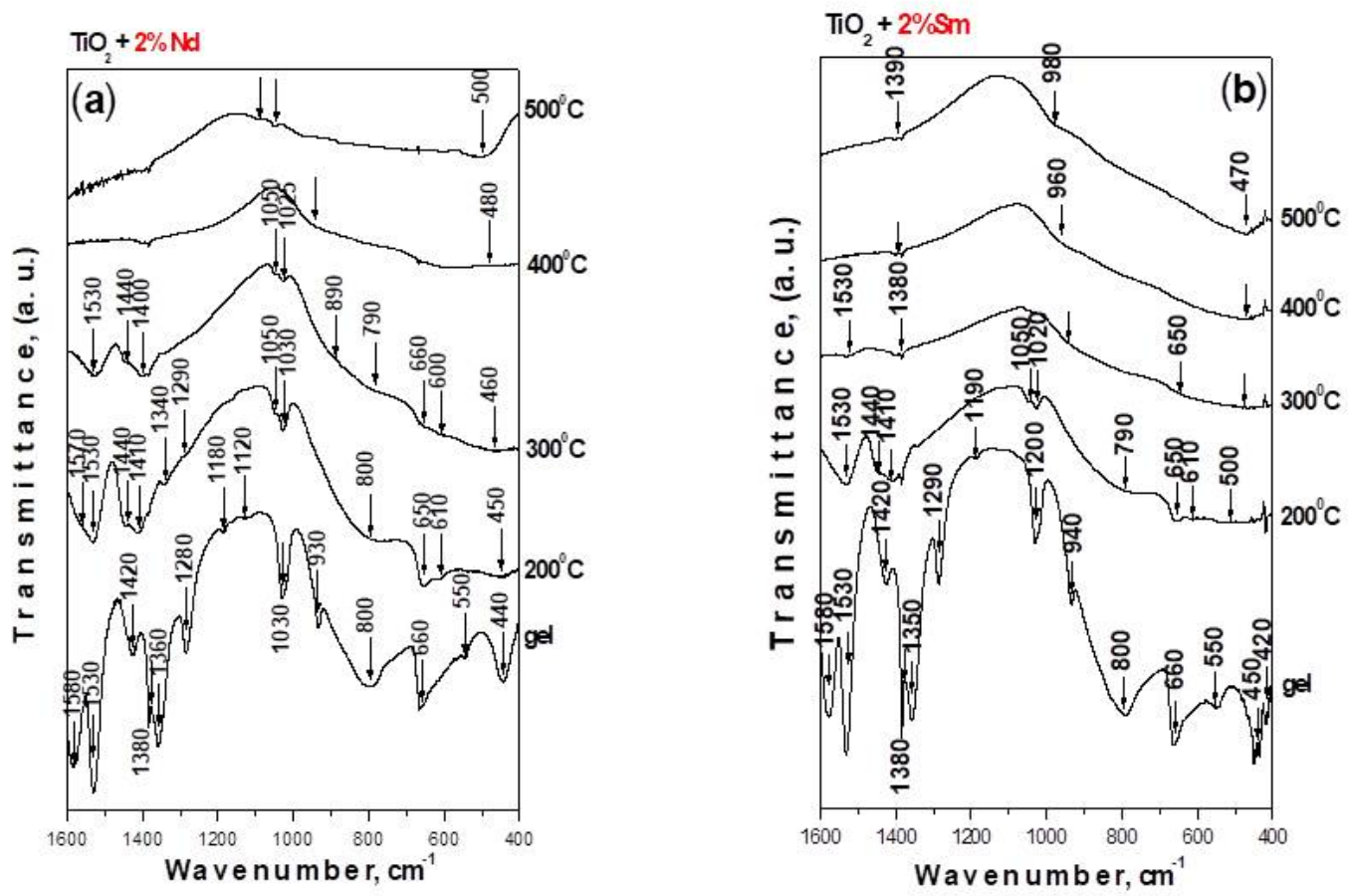

Figure 5. IR spectra of $\mathrm{Ti}(\mathrm{IV})$ isopropoxide modified with (a) $2 \% \mathrm{Nd}$ and (b) $2 \% \mathrm{Sm}$.

\section{UV-Vis Spectroscopy}

Aiming to evaluate the completeness of the hydrolysis-condensation processes, as well as to gain additional structural information, UV-Vis spectroscopy has been applied. Figure 6 shows the spectra of as-prepared TN and TS gels, which are compared to those of $\mathrm{TiO}_{2}$ gel obtained from Ti(IV) isopropoxide. The interpretation of the UV-Vis spectra is made 
on the basis of literature data as well as our previous results obtained in various systems containing $\mathrm{TiO}_{2}$ [21,44,49,52-54,57]. In Figure 6, several peaks could be distinguished: for undoped $\mathrm{TiO}_{2}-250,320 \mathrm{~nm}$ while for the Sm- and $\mathrm{Nd}$-modified $\mathrm{TiO}_{2}-260 \mathrm{~nm}$ as well as one broad band in the region 345-365 $\mathrm{nm}$.

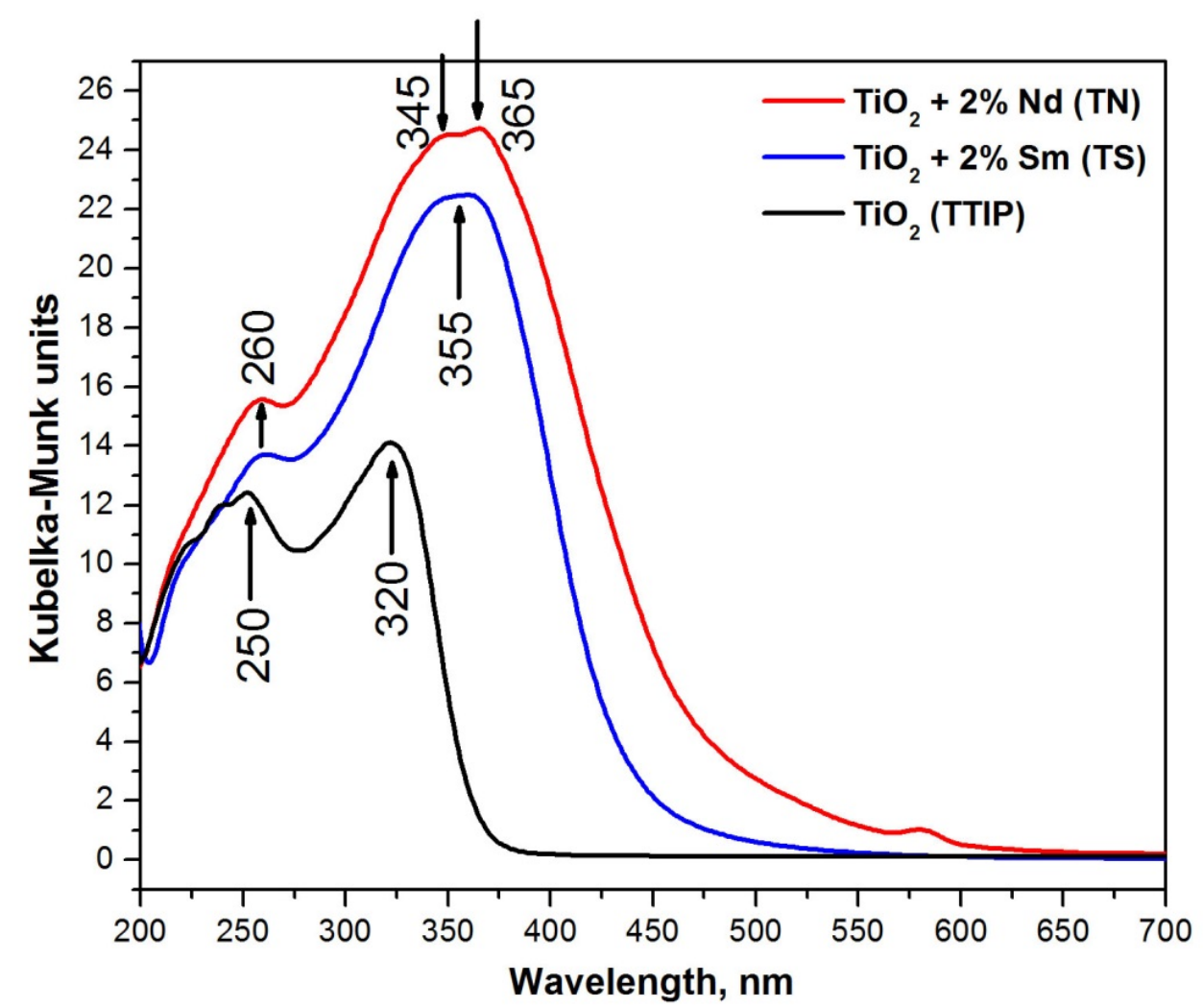

Figure 6. DR UV-Vis spectra of TN, TS, and pure Ti(IV) isopropoxide gels.

As it is known, the isolated $\mathrm{TiO}_{4}$ units exhibited the ligand-to-metal charge transfer band in the region 200-260 nm, while in a titania network (anatase), the charge transfer in $\mathrm{TiO}_{6}$ groups is above $300 \mathrm{~nm}$ data [49]. During the hydrolysis-condensation processes, coordination geometry is changed and as a result, polymerized Ti species (Ti-O-Ti links between $\mathrm{TiO}_{6}$ units) are formed $[49,52-54,57]$. Hence, an increase in the UV absorption peak above $300 \mathrm{~nm}$ (instead of that at 250-260 nm) occurred. Bearing in mind the higher intensity of the bands above $300 \mathrm{~nm}$ in comparison to these below $300 \mathrm{~nm}$ for the Sm and Ndmodified $\mathrm{TiO}_{2}$ samples, it could be suggested that the hydrolysis-condensation processes are more complete in these samples in comparison to the undoped $\mathrm{TiO}_{2}$. Moreover, the widening of the band in the range $345-365 \mathrm{~nm}$ could be also attributed to the $\mathrm{f}-\mathrm{f}$ transitions of $\mathrm{Sm}^{3+}$ or $\mathrm{Nd}^{3+}[58,59]$.

UV-Vis spectroscopy was also used in order to investigate the optical properties of the investigated samples (Table 1). As can be seen, a red shift of the absorption edge in the Sm- and Nd-doped $\mathrm{TiO}_{2}$ powders (431.98 $\mathrm{nm}-2 \% \mathrm{Sm}$ and $474.24 \mathrm{~nm}-2 \% \mathrm{Nd}$ ) is clearly observed in comparison to pure $\mathrm{TiO}_{2}$ gel $(367.69 \mathrm{~nm})$. It is obvious that the TN sample exhibited a higher cut-off value $(474.24 \mathrm{~nm})$ and increased absorption in the Vis region. The red shift in the doped samples can be ascribed to the charge transfer between the $\mathrm{TiO}_{2}$ valence band and $4 \mathrm{f}$ levels of modified ions $\left(\mathrm{Nd}^{3+}\right.$ and $\left.\mathrm{Sm}^{3+}\right)$ [21]. 
Table 1. Observed cut-off and calculated optical band gap values $\left(E_{g}\right)$ of the obtained gels.

\begin{tabular}{ccc}
\hline \multirow{2}{*}{ Gels Composition, mol \% } & \multicolumn{2}{c}{ UV-Vis Results } \\
\cline { 2 - 3 } & $\boldsymbol{E}_{\boldsymbol{g}, \mathbf{e V}}$ & Cut-Off, $\mathbf{n m}$ \\
\hline $\mathrm{TiO}_{2}$ (Ti(IV) isopropoxide) & 3.37 & 367.69 \\
$\mathrm{TS}(2 \% \mathrm{Sm})$ & 2.90 & 431.98 \\
$\mathrm{TN}(2 \% \mathrm{Nd})$ & 2.61 & 474.24 \\
\hline
\end{tabular}

Another peculiarity of the UV-Vis spectrum of TN gel is the presence of a weak peak in the visible region $(\sim 580 \mathrm{~nm})$ which could be attributed to the $\mathrm{f}-\mathrm{f}$ electronic transition to $\mathrm{Nd}^{3+}$ in the coordination environment of $\mathrm{TiO}_{2}$ nanostructures $[60,61]$. The calculated optical band gap values $\left(E_{g}\right)$ of pure and modified $\mathrm{TiO}_{2}$ gels are $3.37,2.90,2.61 \mathrm{eV}$, respectively (Table 1). Our findings correlate well to those obtained by other teams [22,25,62].

\subsection{Photocatalytic and Antibacterial Properties}

\subsubsection{Photocatalytic Activity}

The photocatalytic action of pure and modified $\mathrm{TiO}_{2}$ powders heated at $500{ }^{\circ} \mathrm{C}$ for $1 \mathrm{~h}$ was tested for degradation of MG dye water solution illuminated with UV and visible light. As it is well known, MG was selected as a model pollutant because of its intensive use in industrial processes. The degradation ratios $(\mathrm{C} / \mathrm{Co})$ of $\mathrm{MG}$ as a function of time for all samples were investigated and it is represented in Figure 7a,b. Blank tests of the photodegradation of the dye in the absence of a photocatalyst indicate that the photolysis can be ignored as less than $2 \%$ of MG was removed after $2 \mathrm{~h}$ illumination under UV or visible light. The MG dye degradation was also followed in the presence of Degussa P25 $\mathrm{TiO}_{2}$ in order to evaluate the photocatalytic ability of synthesized powders in comparison with the key photocatalyst (Figure 7a,b). It was found that the photocatalytic performance under UV light of sample TS is better than that of TN and pure $\mathrm{TiO}_{2}$ samples under the same conditions (Figure 7a). It is believed that small particle size and large specific surface area could be beneficial for photocatalytic activity. The particle size of the Nd-doped $\mathrm{TiO}_{2}$ was found to be about $10 \mathrm{~nm}$ (Figure 2). However, as the particle size is lowered below a certain limit, surface recombination processes can become dominant because of the increased surface-to-volume ratio and an optimum particle size for maximum photocatalytic efficiency exists [63]. Probably the lower photoactivity of the sample TN could be explained by the small size of its particles.

Bearing in mind the obtained experimental results it could be suggested that the specific surface area has little effect on the photocatalytic activity. Despite its lower specific surface area $\left(81 \mathrm{~m}^{2} / \mathrm{g}\right)$ sample TS exhibited better photocatalytic properties in comparison to TN one $\left(118 \mathrm{~m}^{2} / \mathrm{g}\right)$. According to Sun et al. [8], the possible reason could be the crystallization of $\mathrm{TiO}_{2}$ (anatase) at the earlier temperature of $400{ }^{\circ} \mathrm{C}$ while the $\mathrm{TN}$ sample preserved the amorphous state at the same temperature, as shown in Figure 2. As was already found, the anatase phase can contain more adsorbed water and hydroxyl groups on the surface of titania which helps to improve the photocatalytic activity of TS sample [8]. These data compare well with those obtained by XRD where it was shown that the $\mathrm{Nd}$ doping hinders earlier growth of $\mathrm{TiO}_{2}$ (anatase) particles (Figure 2).

The results of the photocatalytic test under illumination with visible light (Figure 7b) reveal that dopping with $\mathrm{Nd}$ and $\mathrm{Sm}$ was not beneficial for the degradation of the MG dye at our experimental conditions. As can be seen in Figure $7 \mathrm{~b}$, the photocatalytic performance of synthesized $\mathrm{TiO}_{2}$ under visible light is comparable to that of the best commercial photocatalyst Degussa P25.

The absorbance spectra of MG versus visible light illumination time for the synthesized photocatalyst are shown in Figure 8. As irradiation time increases the height of peak at $618 \mathrm{~nm}$ decreases, which is a result of photocatalytic degradation of MG. 

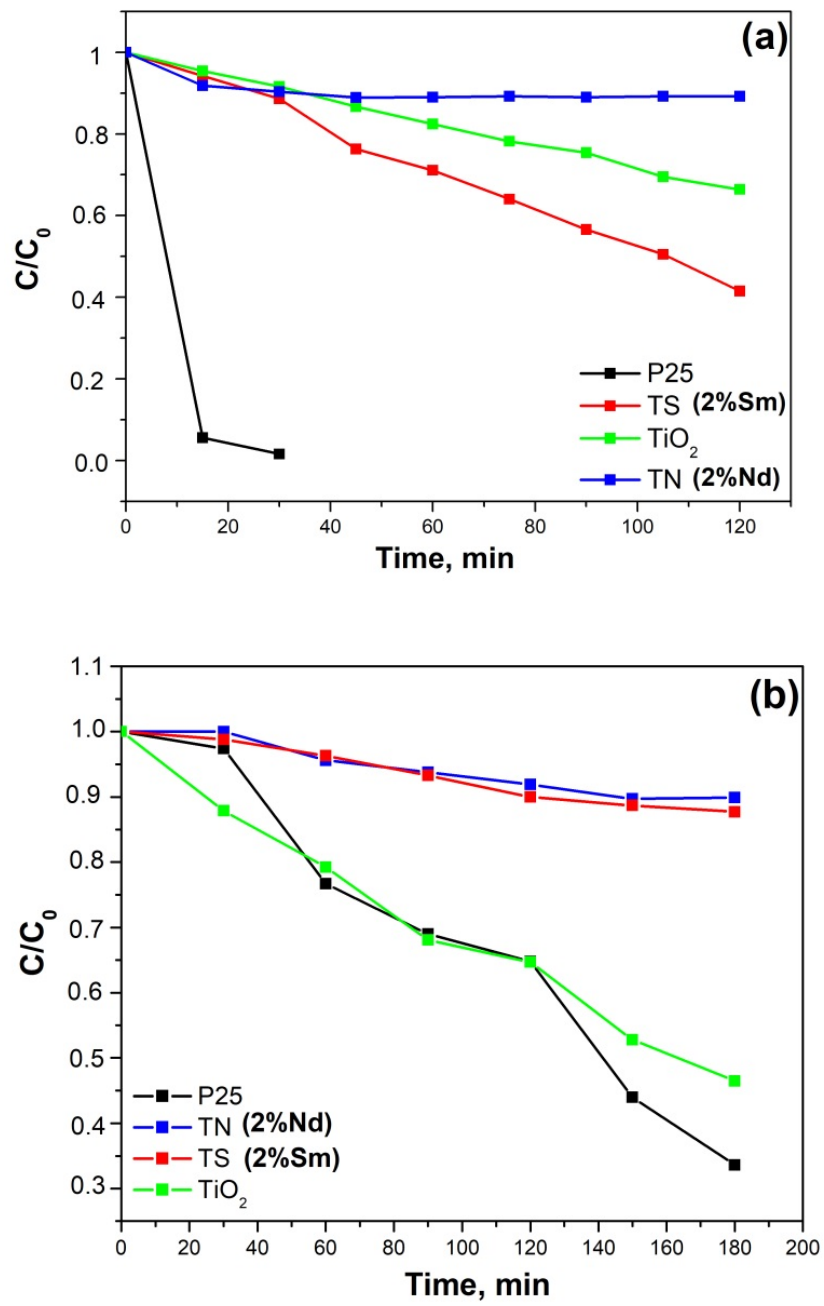

Figure 7. Photocatalytic activity against Malachite green of both samples $\mathrm{TiO}_{2} / 2 \% \mathrm{Nd}$ and $\mathrm{TiO}_{2} / 2 \% \mathrm{Sm}$ compared to pure $\mathrm{TiO}_{2}$ obtained by metal alkoxide and Degussa P25: (a) under UV irradiation; (b) under Vis irradiation.

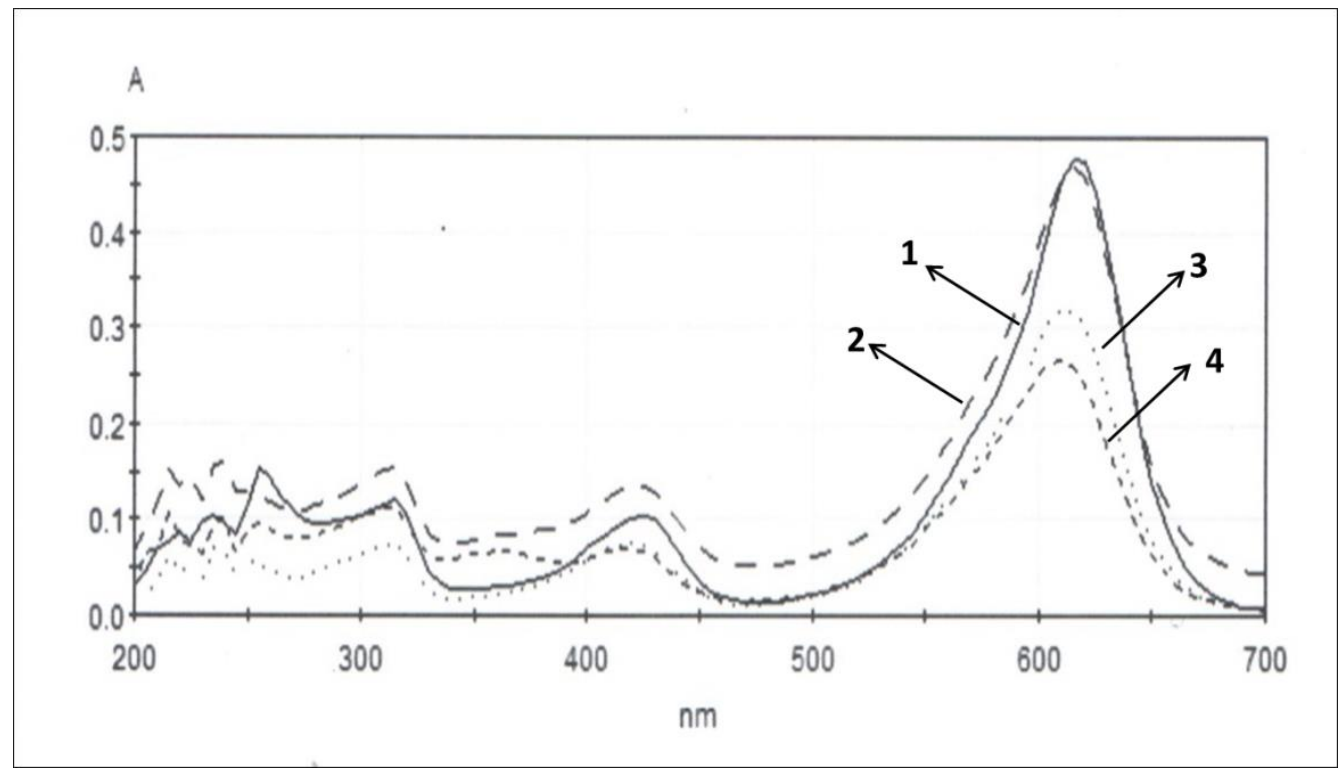

Figure 8. Change in the absorbance spectra of MG with the illumination time in the presence of synthesized by metal alkoxide $\mathrm{TiO}_{2}$ after: $0 \mathrm{~min}(\mathbf{1}) ; 60 \mathrm{~min}(2) ; 120 \mathrm{~min}(3) ; 180 \mathrm{~min}(4)$ of Vis irradiation. 
It is well-documented in the literature that the initial step in the $\mathrm{TiO}_{2}$-mediated photocatalysed degradation involves the generation of electron-hole $(\mathrm{e}-/ \mathrm{h}+)$ pair, leading to the formation of hydroxyl radical $(\bullet \mathrm{OH})$ and superoxide radical anion $\left(\mathrm{O}_{2} \bullet^{-}\right)$. It has been suggested that these radicals are the primary oxidizing species in the photocatalytic oxidation processes and are highly reactive to attack the organic molecules [1-3]. The literature confirms that the appropriate dopping influences the photoactivity by electron or hole traps. When such a trap can cause formation of highly reactive species, the dopant introduction has a positive effect. If dopant introduction cannot decrease electron-hole recombination, such modification is ineffective in the degradation process $[64,65]$.

The disagreements under visible and UV irradiations can be explained by whether the dopants act as electron and hole trappers or as recombination center of both the charges.

It can be suggested that the lower photocatalytic efficiency of doped samples in this study can be explained by the prevalence of the recombination processes.

As it is known, the photocatalytic activity of doped $\mathrm{TiO}_{2}$ depends on many factors, such as synthesis procedure, amount of dopant, light source, particle size, surface area, etc. Obviously, at our experimental conditions, the modification with ions of $\mathrm{Nd}$ and $\mathrm{Sm}$ did not impove the photoactivity under visible light illumination.

\subsubsection{Antibacterial Activity}

The antibacterial activity of the investigated materials was tested against strains B. subtilis NBIMCC 3562 and E. coli NBIMCC K12 by measuring the inhibition zones formed around the materials and monitoring the dynamic of bacterial growth in their presence in a liquid medium. As well, the antibacterial properties of samples TS and TN were compared to those of the sol-gel-derived $\mathrm{TiO}_{2}$. The growth-inhibiting effect of the materials against the two bacterial strains was shown in Figure 9. Compared to the control samples (without materials added), all samples exhibited good antibacterial activity against both bacterial strains but their behavior during the analyses is different. It is worth noting that the TN sample showed the highest growth inhibition (about 77\%) against the Grampositive B. subtilis NBIMCC 3562, while the TS one demonstrated 100\% growth inhibition against the Gram-negative E. coli NBIMCC K12 (Figure 8). The other two samples showed similar antibacterial activity (about 70\% growth inhibition) towards both bacterial strains.

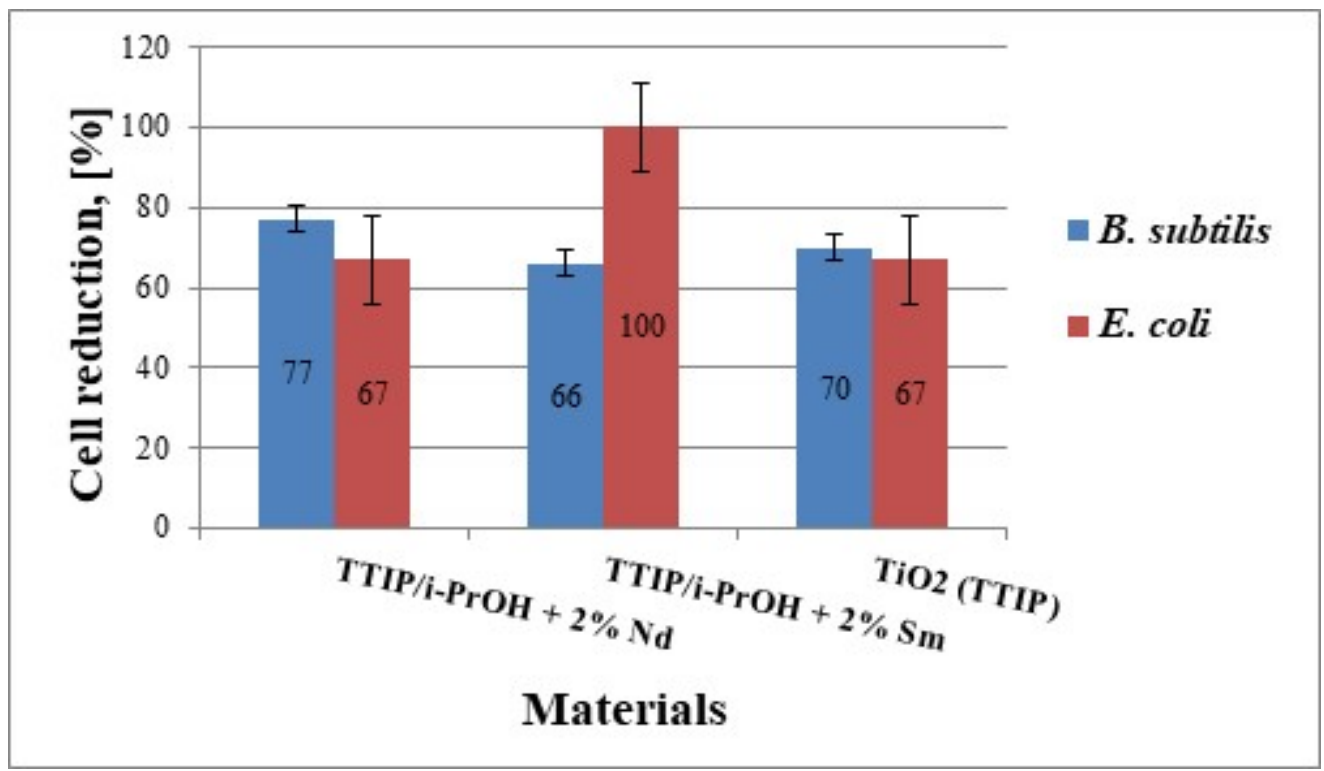

Figure 9. Cell reduction of $B$. subtilis NBIMCC 3562 and E. coli $\mathrm{NBIMCC} \mathrm{K} 12$ by $\mathrm{TiO}_{2} / 2 \% \mathrm{Nd}, \mathrm{TiO}_{2} / 2 \% \mathrm{Sm}$ and $\mathrm{pure} \mathrm{TiO}_{2}$. Data are expressed as means $\pm \mathrm{SD}(\mathrm{n}=3)$. Error bars denote the standard deviations of three trials. 
Another approach applied to estimate the antibacterial properties of the investigated samples refers to the measurement of the zones, which are free of bacterial growth. The obtained results revealed well-formed inhibition zones around materials, containing TS, $\mathrm{TN}$ and undoped $\mathrm{TiO}_{2}$. Comparison between results obtained showed that materials exhibited higher antibacterial activity against B. subtilis NBIMCC 3562 than E. coli NBIMCC K12. Also, the TS ( $2 \% \mathrm{Sm})$ sample demonstrated the highest antibacterial activity against B. subtilis NBIMCC 3562 (inhibition zone $=20 \mathrm{~mm}$ ), whereas the lowest one was observed in the pure $\mathrm{TiO}_{2}$ sample (inhibition zone $=13 \mathrm{~mm}$ ) (Figure 10). The highest inhibition zone against $E$. coli NBIMCC $\mathrm{K} 12$ was observed in the TN $(2 \% \mathrm{Nd})$ sample (inhibition zone $=14.5 \mathrm{~mm}$ ). The pure $\mathrm{TiO}_{2}$ sample again showed the lowest antibacterial activity against the Gram-negative test microorganism (inhibition zone $=11 \mathrm{~mm}$ ).
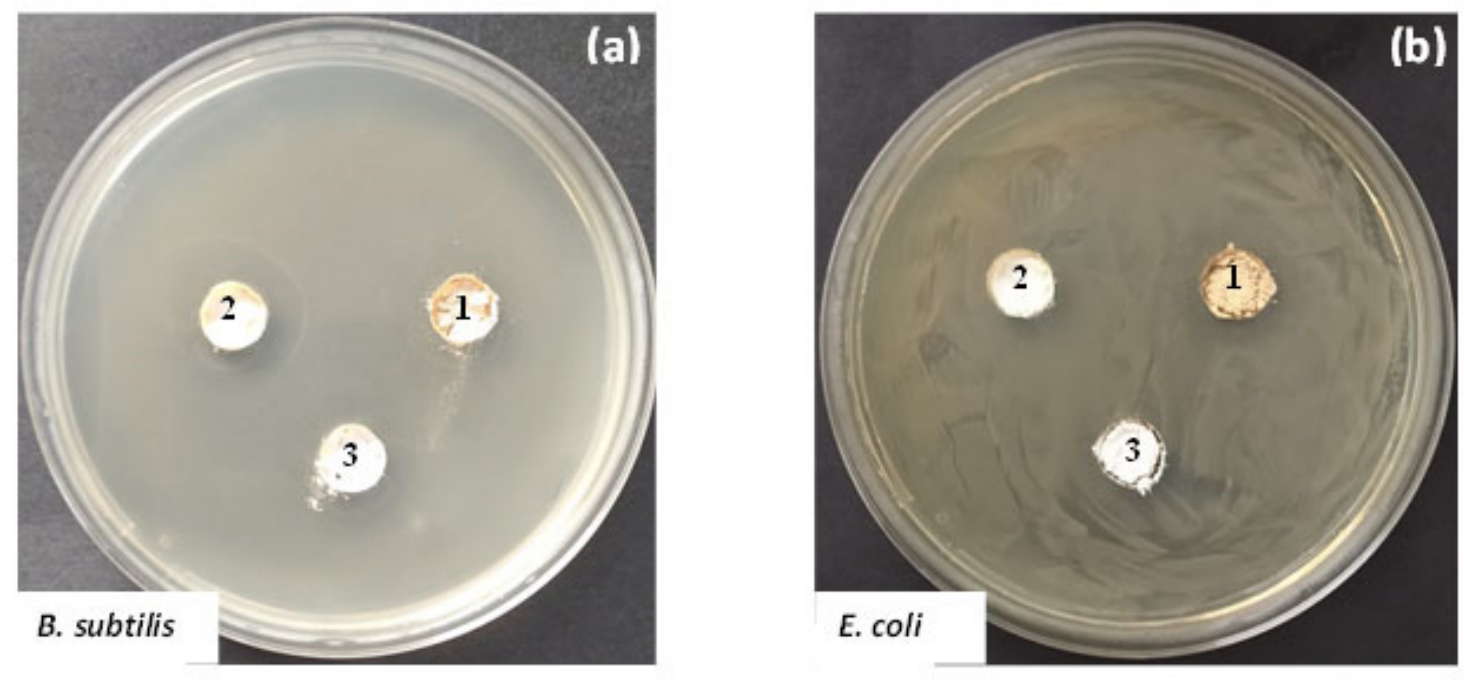

Figure 10. Antibacterial properties of samples $\mathrm{TiO}_{2} / 2 \% \mathrm{Nd}(1), \mathrm{TiO}_{2} / 2 \% \mathrm{Sm}$ (2) and.pure $\mathrm{TiO}_{2}$ (3) obtained by metal alkoxide against B. subtilis NBIMCC 3562 (a) and E. coli NBIMCC K12 (b).

The high antibacterial activity of the modified with $\mathrm{Sm}$ and $\mathrm{Nd} \mathrm{TiO}_{2}$ samples could be explained with their lower bandgap which enhances the visible light absorption ability. On the other hand, their relatively higher surface area also results in the formation of highly reactive oxygen species (ROS) which are responsible for bacterial cell damage. Our results compare well to those obtained by other authors [25].

\section{Materials and Methods}

\subsection{Materials and Reagents}

Ti(IV) isopropoxide-TTIP ( $>98 \%$, Merck, Darmstadt, Germany) Neodymium oxide, $\mathrm{Nd}_{2} \mathrm{O}_{3}$ (99,9\%, Janssen Chimica, Antwerpen, Belgium), Samarium oxide, $\mathrm{Sm}_{2} \mathrm{O}_{3}$ (Janssen Chimica, Anwerpen, Belgium 99.9\%) and isopropanol, i-PrOH (>99.5\%, Merck, Darmstadt, Germany) have been used as main precursors for the obtaining titania powders. The acetylacetonate (AcAc, Sigma-Aldrich, Darmstadt, Germany) was used as a chelating agent to form stable complexes with TTIP. Commercial Degussa $\mathrm{P} 25 \mathrm{TiO}_{2}$ powder was kindly donated by Evonik Industries AG. All the reagents used were of analytical grade and were used without further purification.

\subsection{Preparation of $\mathrm{Nd}$ and $\mathrm{Sm}$-Modified $\mathrm{TiO}_{2}$ Gels}

The experimental conditions for obtaining the initial solutions consist of several steps. The first solution was prepared by mixing of TTIP, i-PrOH and AcAc with vigorous stirring while keeping the molar ratio TTIP $/ \mathrm{C}_{3} \mathrm{H}_{7} \mathrm{OH} / \mathrm{AcAc}=1: 30: 1$ [66]. Several drops of nitric acid were added to obtain a clear solution. During the procedure, the molar ratio of AcAc/TTIP >2 was preserved. The obtained sol was transparent, with an orange color 
indicating the retention of the AcAc ligand in the xerogel [67]. The other solution was obtained by $\mathrm{Nd}_{2} \mathrm{O}_{3}$ or $\mathrm{Sm}_{2} \mathrm{O}_{3}$ dissolved in $1.5 \mathrm{~mL} \mathrm{HNO}_{3}$ and isopropanol. Finally, both solutions were mixed with vigorous stirring. During the experimental procedure, no additional water was added. The sol-gel hydrolysis reaction was accomplished only in the presence of air moisture. The $\mathrm{pH}$ of the resulting solution was measured and found equal to 4-5. The gels' ageing was performed in air for several days in order to allow further hydrolysis. Aiming to verify the phase transformations, all gels were subjected to stepwise heating in air from $200{ }^{\circ} \mathrm{C}$ to $700{ }^{\circ} \mathrm{C}$ for $1 \mathrm{~h}$ exposure time at each temperature value. The investigated samples were denoted as follows: (TTIP, TTIP/i-PrOH, TN (TTIP$2 \% \mathrm{Nd}$ ) and TS (TTIP- $2 \% \mathrm{Sm}$ ). It has to be mentioned that the dopant concentration has been chosen based on several reasons: i.e., the literature survey on the $\mathrm{TiO}_{2}$ doping, our previous investigations $[42,43]$ as well as the necessity of satisfactory performance against degradation of the selected organic dye and antibacterial test.

\subsection{Characterization}

The thermal stability of selected gels was determined by differential thermal analysis (LABSYSTM EVO apparatus) with $\mathrm{Pt}-\mathrm{Pt} / \mathrm{Rh}$ thermocouple at a heating rate of $10 \mathrm{~K} / \mathrm{min}$ in air flow, using $\mathrm{Al}_{2} \mathrm{O}_{3}$ as a reference material. The accuracy of the temperature was $\pm 5{ }^{\circ} \mathrm{C}$. Heating of the samples was limited up to $600^{\circ} \mathrm{C}$. Gases evolved (EGA) during the thermal treatments were analyzed by mass spectrometry (MS) with a Pfeiffer OmniStarTM mass spectrometer (Pfeiffer Vacuum Technology AG, Wetzlar, Germany). Mass spectra recorded for TTIP and TTIP/i-PrOH (Figure $4 \mathrm{~b}, \mathrm{~d}$ ) show $\mathrm{m} / z$ of $14,15,18$ and 44 ascribed to $\mathrm{CH}_{2}, \mathrm{CH}_{3}$, $\mathrm{H}_{2} \mathrm{O}$ and $\mathrm{CO}_{2}$, respectively. Powder XRD patterns were registered at room temperature with a Bruker D8 Advance diffractometer using $\mathrm{Cu}-\mathrm{K}_{\alpha}$ radiation. The specific surface area of samples heat-treated at $500{ }^{\circ} \mathrm{C}$ was measured using BET analysis (Quantachrome Instruments NOVA 1200e apparatus, Anton Paar GmbH, Graz, Austria). The optical absorption spectra of the powdered samples in the wavelength range $200-1000 \mathrm{~nm}$ were recorded by a UV-VIS diffused reflectance Spectrophotometer "Evolution 300" (Thermo Electron Corporation, Madison, WI, USA) using a magnesium oxide reflectance standard as the baseline. The absorption edge and the optical band gap were determined following Dharma et al. instructions [29]. The band gap energies $\left(E_{g}\right)$ of the samples were calculated by the Planck's equation, where $E_{g}$ is the band gap energy $(\mathrm{eV}), h$ is the Planck's constant, $c$ is the light velocity $(\mathrm{m} / \mathrm{s})$, and $\lambda$ is the wavelength $(\mathrm{nm})$. The infrared spectra were registered in the range $1600-400 \mathrm{~cm}^{-1}$ using the $\mathrm{KBr}$ pellet technique on a Nicolet-320 FTIR spectrometer with 64 scans and a resolution of $\pm 1 \mathrm{~cm}^{-1}$.

$$
E_{g}=\frac{h \cdot c}{\lambda}=\frac{1240}{\lambda}
$$

\subsection{Photocatalytic Experiments}

The photocatalytic activities of pure and modified with $\mathrm{Nd}$ and $\mathrm{Sm} \mathrm{TiO}_{2}$ powders were characterized by photodegradation of the dye malachite green (MG) as a model pollutant. For the degradation experiments, the initial concentration of the MG aqueous solution was $5 \mathrm{ppm}$. A fixed amount of $100 \mathrm{mg}$ of each catalyst was added to $150 \mathrm{~mL}$ dye solution to form suspension and the suspensions were sonicated for $10 \mathrm{~min}$. Before irradiation, the suspensions were magnetically stirred in the dark for $30 \mathrm{~min}$ in order to establish an adsorption-desorption equilibrium of the dye on the catalyst surface. The time at which the light was turned on was noted as starting point $(t=0)$ of the reaction at which time the concentration of the dye was denoted as $C_{0}$.

Irradiation with UV-light was provided by a black light blue lamp (Sylvania BLB $50 \mathrm{~Hz}$ $8 \mathrm{~W}$ T5, (Erlangen, Germany) with the major fraction of irradiation occurring at $365 \mathrm{~nm}$. The lamp was fixed at $10 \mathrm{~cm}$ above the solution surface. The visible light source was a $500 \mathrm{~W}$ halogen lamp (Sylvania, Erlangen, Germany) fixed at $40 \mathrm{~cm}$ above the treated solution. All photocatalytic tests were performed at a constant stirring rate $(450 \mathrm{rpm})$ and room temperature of $25^{\circ} \mathrm{C}$. Sampling was performed at regular intervals during the reaction. 
In order to separate the supernatant liquid from the solid particles the collected aliquot samples of the dye mixtures were centrifuged at $5000 \mathrm{rpm}$ for $10 \mathrm{~min}$. The phototocatalytic degradation of the dye was monitored by measuring the absorbances of clear supernatant aliquots by Jenway 6505 UV-Vis (designed and manufactured in UK) and Jenesys $10 \mathrm{~S}$ UV-Vis spectrophotometers (made in China, design by USA) at the maximum absorption wavelength of MG-618 nm. The experimental data are the average from two or three measurements differing from each other by about $5 \%$.

\subsection{Antibacterial Assay}

3.5.1. Test Microorganisms, Media and Culture Conditions

The bacterial strains Bacillus subtilis NBIMCC 3562 and Escherichia coli NBIMCC K12 were selected as test microorganisms and were obtained from the National Bank for Industrial Microorganisms and Cell Cultures (NBIMCC, Bulgaria). Exponential cultures $(\mathrm{OD} 610 \mathrm{~nm}=1.9)$ of both strains were obtained in Nutrient broth (NB)/Luria-Bertani (LB) broth, after cultivation in a shaker-incubator ES-20/60 (Biosan, Riga, Latvia, $120 \mathrm{rpm}$ ) at $30 / 37^{\circ} \mathrm{C}$ for $24 \mathrm{~h}$.

\subsubsection{Antimicrobial Activity Assay}

The bacterial growth-inhibiting effect of the tested materials was investigated by studying the reduction of viable cells after exposure to them. To this end, $100 \mu \mathrm{L}$ strain suspension of B. subtilis NBIMCC 3562 or E. coli NBIMCC K12, pre-adjusted to the turbidity of a $0.5 \mathrm{McF}$ arland standard, and $10 \mathrm{mg}$ of each material were added to flasks, containing $100 \mathrm{~mL}$ NB or LB broth, respectively. Samples, containing only bacterial cells (without materials added), were used as controls. The incubation process was performed on a shakerincubator $(120 \mathrm{rpm})$ at $30 / 37^{\circ} \mathrm{C}$ for $24 \mathrm{~h}$. The antibacterial activity of the investigated materials was determined by cell counts, calculated from the colonies, grown on NB/LB agar after $24 \mathrm{~h}$ of incubation at $30 / 37^{\circ} \mathrm{C}$ and expressed as a percentage of cell reduction, according to Bachvarova-Nedelcheva et al. [33]. All tests were performed in triplicates and the results obtained showed the mean values.

In addition, the antibacterial activity of the materials against the two test microorganisms was also determined by the agar-well diffusion method [68]. Sterile NB/LB agar plates were inoculated with an exponential culture of the test strains, according to the spread-plate method. The investigated materials in the amount of $100 \mathrm{mg}$ were loaded onto the marked wells in the agar plates and were then cultured in an incubator (Binder, Germany) at $30 / 37^{\circ} \mathrm{C}$ for $24 \mathrm{~h}$. The antibacterial activity was assessed by measuring the diameter of the obtained inhibition zones. Three replicates were made from each sample and the results show the mean values.

\section{Conclusions}

Transparent samarium- and neodymium-modified titania gels are prepared from Ti(IV) isopropoxide. The key role of the chelating agent (AcAc) for obtaining gels on the ground of Ti(IV) isopropoxide and isopropanol is confirmed. The presence of neodymium stabilizes the amorphous state of the sample up to higher temperature $\left(400{ }^{\circ} \mathrm{C}\right)$ as compared to the other one containing samarium. It was established that the neodymium and samarium doping hinders the anatase-to-rutile phase transition and enhances the stability of the anatase phase at higher temperature values $\left(700^{\circ} \mathrm{C}\right)$. The DTA revealed that in the presence of samarium, the organic combustion occurs at higher temperatures (of $340^{\circ} \mathrm{C}$ ) when compared to that of neodymium (of $250{ }^{\circ} \mathrm{C}$ ). The UV-Vis results showed that the investigated gels exhibited a red shifting of the cut-off in comparison to the pure sol-gelderived $\mathrm{TiO}_{2}$ gel. Using IR spectroscopy, it was found that a more completed hydrolysis reaction occurred in the $\mathrm{TiO}_{2}$ sample modified with samarium. The photocatalytic activity under UV light of modified with Sm sample was better than that of Nd-modified and synthesized pure $\mathrm{TiO}_{2}$ sample. The doping with $\mathrm{Nd}$ and $\mathrm{Sm}$ was not beneficial for the degradation of the MG dye under visible light. However, the photoactivity of synthesized 
$\mathrm{TiO}_{2}$ under the same conditions was comparable to that of the commercial photocatalyst Degussa P25. The materials obtained demonstrated good antibacterial activity against B. subtilis 3562 and E. coli $\mathrm{K} 12$. It is found that the $\mathrm{Sm}$-modified $\mathrm{TiO}_{2}$ is more sensitive against $B$. subtilis, while $\mathrm{Nd}$-doped $\mathrm{TiO}_{2}$ exhibited $100 \%$ reduction of cells against $E$. coli.

Author Contributions: Conceptualization, R.I., A.B.-N. and S.Y.; methodology, R.I., A.B.-N. and I.S.; Antibacterial properties N.G., V.N.; Photocatalytic tests, A.S.; writing—original draft preparation, A.B.-N. and S.Y.; supervision, R.I. All authors have read and agreed to the published version of the manuscript.

Funding: This research received no external funding.

Institutional Review Board Statement: Not applicable.

Informed Consent Statement: Not applicable.

Data Availability Statement: The data presented in this study are available on request from the corresponding author.

Acknowledgments: The authors are thankful to the project D01-272/02.10.2020_“European Network on Materials for Clean Technologies", under the National Program "European Scientific Networks".

Conflicts of Interest: The authors declare no conflict of interest.

Sample Availability: Not available.

\section{References}

1. Carp, O.; Huisman, C.L.; Reller, A. Photoinduced reactivity of titanium dioxide. Prog. Solid State Chem. 2004, 32, 33-177. [CrossRef]

2. Gupta, S.M.; Tripathi, M. A review of $\mathrm{TiO}_{2}$ nanoparticles. Chin. Sci. Bull. 2011, 56, 1639-1657. [CrossRef]

3. Zaleska, A. Doped-TiO 2 : A Review. Recent Pat. Eng. 2008, 2, 157-164. [CrossRef]

4. Fagan, R.; McCormack, D.E.; Dionysiou, D.D.; Pillai, S.C. A Review of solar and visible light active TiO $\mathrm{T}_{2}$ photocatalysts for treating bacteria, cyanotoxins and contaminants of emerging concern. Mater. Sci. Semicond. Proc. 2016, 42, 2-14. [CrossRef]

5. Kumar, S.G.; Devi, L.G. Review on modified $\mathrm{TiO}_{2}$ photocatalysts under UV/Visible light: Selected results and related mechanisms on interfacial charge carrier transfer dynamics. J. Phys. Chem. A 2011, 115, 13211-13241. [CrossRef]

6. Parnicka, P.; Mazierski, P.; Grzyb, T.; Lisowski, W.; Kowalska, E.; Ohtani, B.; Zaleska-Medynska, A.; Nadolna, J. Influence of the preparation method on the photocatalytic activity of $\mathrm{Nd}-$ Modified $\mathrm{TiO}_{2}$. Beilstein J. Nanotechnol. 2018, 9, 447-459. [CrossRef]

7. Reszczyńska, J.; Grzyb, T.; Sobczak, J.W.; Lisowski, W.; Gazda, M.; Ohtani, B.; Zaleska, A. Visible light activity of rare earth metal doped $\left(\mathrm{Er}^{3+}, \mathrm{Yb}^{3+}\right.$ or $\left.\mathrm{Er}^{3+} / \mathrm{Yb}^{3+}\right)$ titania photocatalysts. Appl. Catal. B Environ. 2015, 163, 40-49. [CrossRef]

8. Sun, D.; Wang, K.; Xu, Z.; Li, R. Synthesis and photocatalytic activity of sulfate modified Nd-doped TiO ${ }_{2}$ under visible light irradiation. J. Rare Earths 2015, 33, 491-497. [CrossRef]

9. Parnicka, P.; Mazierski, P.; Grzyb, T.; Wei, Z.; Kowalska, E.; Ohtani, B.; Klimczuk, T.; Nadolna, J. Preparation and photocatalytic activity of Nd-modified $\mathrm{TiO}_{2}$ photocatalysts: Insight into the excitation mechanism under visible light. J. Catal. 2017, 353, 211-222. [CrossRef]

10. Zhang, H.; Sheng, Y.; Song, Y.; Li, H.; Huang, J.; Zheng, K.; Huo, Q.; Xu, X.; Zou, H. Uniform hollow TiO 2 :Sm ${ }^{3+}$ spheres: Solvothermal synthesis and luminescence properties. Powder Technol. 2013, 239, 403-408. [CrossRef]

11. Cacciotti, I.; Bianco, A.; Pezzotti, G.; Gusmano, G. Synthesis, thermal behaviour and luminescence properties of rare earth-doped titania nanofibers. Chem. Eng. J. 2011, 166, 751-764. [CrossRef]

12. Yuan, M.; Zhang, J.; Yan, S.; Luo, G.; Xu, Q.; Wang, X.; Li, C. Effect of $\mathrm{Nd}_{2} \mathrm{O}_{3}$ addition on the surface phase of TiO 2 and photocatalytic activity studied by UV Raman spectroscopy. J. Alloys Compd. 2011, 509, 6227-6235. [CrossRef]

13. Mazierski, P.; Lisowski, W.; Grzyb, T.; Winiarski, M.J.; Klimczuk, T.; Mikołajczyk, A.; Flisikowski, J.; Hirsch, A.; Kołakowska, A.; Puzyn, T.; et al. Enhanced photocatalytic properties of lanthanide- $\mathrm{TiO}_{2}$ nanotubes: An experimental and theoretical study. J. Appl. Catal. B Environ. 2017, 205, 376-385. [CrossRef]

14. Qin, Y.; Hu, Z.; Lim, B.H.; Chang, W.S.; Chong, K.K.; Zhang, P.; Zhang, H. Sol-hydrothermal synthesis of TiO $2: \mathrm{Sm}^{3+}$ nanoparticles and their enhanced photovoltaic properties. J. Alloys Compd. 2016, 686, 803-809. [CrossRef]

15. Reszczyńska, J.; Grzyb, T.; Wei, Z.; Klein, M.; Kowalska, E.; Ohtani, B.; Zaleska Medynska, A. Photocatalytic activity and luminescence properties of $\mathrm{RE}^{3+}-\mathrm{TiO}_{2}$ nanocrystals prepared by sol-gel and hydrothermal methods. Appl. Catal. B Environ. 2016, 181, 825-837. [CrossRef]

16. Daghrir, R.; Drogui, P.; Robert, D. Modified $\mathrm{TiO}_{2}$ for Environmental Photocatalytic Applications: A Review. Ind. Eng. Chem. Res. 2013, 52, 3581-3599. [CrossRef]

17. Stengl, V.; Bakardjieva, S.; Murafa, N. Preparation and photocatalytic activity of rare earth-doped $\mathrm{TiO}_{2}$ nanoparticles. Mater. Chem. Phys. 2009, 114, 217-226. [CrossRef] 


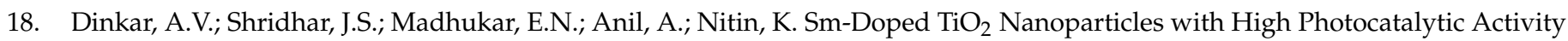
For ARS Dye Under Visible Light Synthesized by Ultrasonic Assisted Sol-Gel Method. Orient. J. Chem. 2016, 32, 933-940. [CrossRef]

19. Kiisk, V.; Reedo, V.; Sild, O.; Sildos, I. Luminescense properties of sol-gel derived $\mathrm{TiO}_{2}$ : Sm powder. Opt. Mater. 2009, 31, 1376-1379. [CrossRef]

20. Xiao, Q.; Si, Z.; Yu, Z.; Qiu, G. Characterization and photocatalytic activity of $\mathrm{Sm}^{3+}$-doped $\mathrm{TiO}_{2}$ nanocrystalline prepared by low temperature combustion method. J. Alloys Compd. 2008, 450, 426-431. [CrossRef]

21. Xu, A.-W.; Gao, Y.; Liu, H.-Q. The Preparation, Characterization, and their Photocatalytic Activities of Rare-Earth-Doped TiO 2 Nanoparticles. J. Catal. 2002, 207, 151-157. [CrossRef]

22. Khade, G.V.; Suwarnkar, M.B.; Gavade, N.L.; Garadkar, K.M. Sol-gel microwave assisted synthesis of Sm-doped TiO 2 nanoparticles and their photocatalytic activity for the degradation of Methyl Orange under sunlight. J. Mater. Sci. Mater. Electr. 2016, 27, 6425-6432. [CrossRef]

23. Chen, R.; Song, W. Facile synthesis and enhanced photocatalysis of Sm doped $\mathrm{TiO}_{2}$. Adv. Mater. Res. 2012, 490-495, 3272-3276.

24. Arasi, S.E.; Madhavan, J.; Ray, M.V.J. Effect of samarium $\left(\mathrm{Sm}^{3+}\right)$ doping on structural, optical properties and photocatalytic activity of titanium dioxide nanoparticles. J. Taibah Univ. Sci. 2018, 12, 186-190. [CrossRef]

25. Bokare, A.; Sanap, A.; Pai, M.; Sabharwal, S.; Athawale, A.A. Antibacterial activities of $\mathrm{Nd}_{\text {doped and } \mathrm{Ag} \text { coated } \mathrm{TiO} 2}$ nanoparticles under solar light irradiation. Colloids Surf. B Biointerfaces 2013, 102, 273-280. [CrossRef]

26. Xu, M.; Da, P.; Wu, H.; Zhao, D.; Zheng, G. Controlled Sn-Doping in $\mathrm{TiO}_{2}$ nanowire photoanodes with enhanced photoelectrochemical conversion. Nano Lett. 2012, 12, 1503-1508. [CrossRef]

27. Jaiswal, S.; McHale, P.; Duffy, B. Preparation and rapid analysis of antibacterial silver, copper and zinc doped sol-gel surfaces. Colloid Surf. B 2012, 94, 170-176. [CrossRef]

28. Luu, C.L.; Nguyen, Q.T.; Ho, S.T. Synthesis and characterization of Fe-doped $\mathrm{TiO}_{2}$ photocatalyst by the sol-gel method. Adv. Nat. Sci. Nanosci. Nanotechnol. 2010, 1, 015008-13. [CrossRef]

29. Bachvarova-Nedelcheva, A.; Iordanova, R.; Stoyanova, A.; Gegova, R.; Dimitriev, Y.; Loukanov, A. Photocatalytic properties of $\mathrm{ZnO} / \mathrm{TiO}_{2}$ powders obtained via combustion gel method. Cent. Eur. J. Chem. 2013, 11, 364. [CrossRef]

30. Shalaby, A.; Angelova, T.; Bachvarova-Nedelcheva, A.; Georgieva, N.; Iordanova, R.; Staneva, A.; Dimitriev, Y. Sol-gel synthesis of materials in the system $\mathrm{SiO}_{2} / \mathrm{ZnO} / \mathrm{TiO}_{2} / \mathrm{RGO}$ and their antimicrobial efficiency against E. coli K12. C. R. Acad. Bulg. Sci. 2016, $69,25-30$.

31. Bachvarova-Nedelcheva, A.; Iordanova, R.; Gegova, R.; Dimitriev, Y. Sol-gel synthesis, characterization and optical properties of $\mathrm{TiO}_{2} / \mathrm{TeO}_{2}$ powders, Bulg. Chem. Commun. 2016, 48, 5-10.

32. Stoyanova, A.; Hitkova, H.; Ivanova, N.; Bachvarova-Nedelcheva, A.; Iordanova, R.; Sredkova, M. Photocatalytic and antibacterial activity of Fe-doped $\mathrm{TiO}_{2}$ nanoparticles prepared by nonhydrolytic sol-gel method, Bulg. Chem. Commun. 2013, 45, 497-504.

33. Bachvarova-Nedelcheva, A.; Iordanova, R.; Stoyanova, A.; Georgieva, N.; Angelova, T. Sol-gel synthesis of Se and Te containing $\mathrm{TiO}_{2}$ nanocomposites with photocatalytic and antibacterial properties. J. Optoel. Adv. Mater. 2016, 18, 5-9.

34. Stoyanova, A.M.; Koleva, T.K.; Bachvarova-Nedelcheva, A.D.; Iordanova, R.S. Photocatalytic Bleaching of Two Organic Dyes Catalyzed by La-Doped Nanosized $\mathrm{TiO}_{2}$. Bulg. Chem. Commun. 2015, 47, 118-124.

35. Stoyanova, A.; Bachvarova-Nedelcheva, A.; Iordanova, R. Photocatalytic degradation of two azo-dyes in single and binary mixture by La modified $\mathrm{TiO}_{2}$. J. Chem. Technol. Metall. 2018, 53, 1173-1178.

36. Stoyanova, A.; Ivanova, N.; Bachvarova-Nedelcheva, A.; Christov, C. Synthesis and photocatalytic activity of cerium-doped and cerium-boron co-doped $\mathrm{TiO}_{2}$ nanoparticles. J. Chem. Technol. Metall. 2021, in press.

37. Bingham, S.; Daoud, W.A. Recent advances in making nano-sized $\mathrm{TiO}_{2}$ visible-light active through rare-earth metal doping. J. Mater. Chem. 2011, 21, 2041-2050. [CrossRef]

38. Saquib, N.; Adnan, R.; Shah, I. A mini-review on rare earth metal-doped $\mathrm{TiO}_{2}$ for photocatalytic remediation of wastewater. Environ. Sci. Pollut. Res. 2016, 23, 1594-1595. [CrossRef]

39. Yadav, S.; Jaiswar, G. Review on Undoped/Doped $\mathrm{TiO}_{2}$ Nanomaterial; Synthesis and Photocatalytic and Antimicrobial Activity. J. Chin. Chem. Soc. 2016, 64, 103-116. [CrossRef]

40. Du, J.; Chen, H.; Yang, H.; Sang, R.; Qian, Y.; Li, Y.; Zhu, G.; Mao, Y.; He, W.; Kang, D.J. A facile sol-gel method for synthesis of porous Nd-doped $\mathrm{TiO}_{2}$ monolith with enhanced photocatalytic activity under UV-Vis irradiation. Microporous Mesoporous Mater. 2013, 182, 87-94. [CrossRef]

41. Nassoko, D.; Li, Y.-F.; Li, J.-L.; Li, X.; Lu, Y. Neodymium-Doped with Anatase and Brookite Two Phases: Mechanism for Photocatalytic Activity Enhancement under Visible Light and the Role of ElectronInternational. J. Photoenergy 2012, $2012,716087$. [CrossRef]

42. Bachvarova-Nedelcheva, A.; Yordanov, S.; Iordanova, R.; Stambolova, I. Comparative study of sol-gel derived pure and Nd-doped $\mathrm{TiO}_{2}$ nanopowders. J. Chem. Technol. Metall. 2018, 53, 1167-1172.

43. Yordanov, S.; Bachvarova-Nedelcheva, A.; Iordanova, R.; Stambolova, I. Sol-gel synthesis and properties of $\mathrm{Sm}_{\mathrm{modified}} \mathrm{TiO}_{2}$ nanopowders. Bulg. Chem. Commun. 2018, 50, 42-48.

44. Yordanov, S.; Bachvarova-Nedelcheva, A.; Iordanova, R. Influence of ethylene glycol on the hydrolysis-condensation behavior of Ti(IV) butoxide. Bulg. Chem. Commun. 2017, 49, 265-270. 
45. Niu, W.; Bi, X.; Wang, G.; Sun, X. $\mathrm{TiO}_{2}$ Gel Thin Film Doped Ce and Sm Preparation and Cyclic Voltammetry Characteristics. Int. J. Electrochem. Sci. 2013, 8, 11943-11950.

46. Huang, F.P. Preparation and photocatalytic property of $\mathrm{Nd}$ doped $\mathrm{TiO}_{2}$ photocatalyst. In Proceedings of the International conference on Manipulation, Manifacturing and Measurment on the Nanoscale (3M-NANO), Xi' an, China, 29 August-1 September 2012; pp. 97-101.

47. Bachvarova-Nedelcheva, A.; Yordanov, S.; Iordanova, R.; Stambolova, I. The solvent role on the hydrolysis-condensation processes and obtaining of $\mathrm{TiO}_{2}$ nanopowders. J. Chem. Technol. Metall. 2019, 54, 292-302.

48. Siwinska-Stefanska, K.; Zdarta, J.; Paukszta, D.; Jesionowski, T. The influence of addition of a catalyst and chelating agent on the properties of titanium dioxide synthesized via the sol-gel method. J. Sol-Gel Sci. Technol. 2015, 75, 264-278. [CrossRef]

49. Gao, X.; Wachs, I.E. Titania-silica as catalysts: Molecular structural characteristics and physico-chemical properties. Catal. Today 1999, 51, 233-254. [CrossRef]

50. Sanchez, J.C.; Henry, M.L.; Babonneau, F. Chemical modification of alkoxide precursor. J. Non Cryst. Sol. 1988, 100, 65-76. [CrossRef]

51. Leustic, A.; Babonneau, F.; Livage, J. Structural investigations of the hydrolysis-condensation process ot titanium alkoxides $\mathrm{Ti}(\mathrm{OR})_{4}(\mathrm{OR}=\mathrm{OPri}, \mathrm{OEt})$ modified by AcAc, 2. From the modified precursor to the colloids. Chem. Mater. 1989, 1, $248-252$. [CrossRef]

52. Barlier, V.; Bounor-Legare, V.; Boiteux, G.; Davenas, J. Hydrolysis-condensation reactions of titanium alkoxides in thin films: A study of the steric hindrance effect by X-ray photoelectron spectroscopy. Appl. Surf. Sci. 2008, 254, 5408-5412. [CrossRef]

53. Gegova, R.; Bachvarova-Nedelcheva, A.; Iordanova, R.; Dimitriev, Y. Synthesis and crystallization of gels in the $\mathrm{TiO}_{2}-\mathrm{TeO}_{2}-\mathrm{ZnO}$ system. Bulg. Chem. Commun. 2015, 47,378-386.

54. Gegova, R.; Iordanova, R.; Bachvarova-Nedelcheva, A.; Dimitriev, Y. Synthesis, structure and properties of $\mathrm{TiO}_{2}-\mathrm{TeO}_{2}-\mathrm{M}_{\mathrm{n}} \mathrm{O}_{\mathrm{m}}(\mathrm{M}$ = Zn, B) gels: A comparison. J. Chem. Technol. Metall. 2015, 50, 449-458.

55. Wang, C.; Xu, B.-Q.; Wang, X.; Zhao, J. Preparation and photocatalytic activity of $\mathrm{ZnO} / \mathrm{TiO}_{2} / \mathrm{SnO}_{2}$ mixture. J. Solid State Chem. 2005, 178, 3500-3506. [CrossRef]

56. Samadi, S.; Yousefi, M.; Khalilian, F.; Tabatabaee, A. Synthesis, characterization, and application of $\mathrm{Nd}, \mathrm{Zr}-\mathrm{TiO} 2 / \mathrm{SiO} 2$ nanocomposite thin films as visible light active photocatalyst. J. Nanostruct. Chem. 2015, 5, 7-15. [CrossRef]

57. Iordanova, R.; Gegova, R.; Bachvarova-Nedelcheva, A.; Dimitriev, Y. Sol-gel synthesis of composites in the ternary $\mathrm{TiO}_{2}-\mathrm{TeO}_{2}-$ $\mathrm{B}_{2} \mathrm{O}_{3}$ system. Phys. Chem. Glasses Eur. J. Glass Sci. Technol. B 2015, 56, 128-138. [CrossRef]

58. Antoinette, M.M.; Israel, S. Synthesis and Characterization of $\mathrm{Sm}_{2} \mathrm{O}_{3}$ Nanoparticles using combustion method. Intern. Res. J. Eng. Technol. 2017, 4, 276-279.

59. Gupta, S.K.; Ghosh, P.S.; Pathak, N.; Arya, A.; Natarajan, V. Understanding the local environment of $\mathrm{Sm}^{3+}$ in doped $\mathrm{SrZrO}_{3}$ and energy transfer mechanism using time resolved luminescence: A combined theoretical and experimental approach. RCS Adv. 2021, in press. [CrossRef]

60. Choudhury, B.; Borah, B.; Choudhury, A. Ce-Nd codoping effect on the structural and optical properties of $\mathrm{TiO}_{2}$ nanoparticles. Mater. Sci. Eng. B 2013, 178, 239-247. [CrossRef]

61. Wang, C.; Ao, Y.; Wang, P.; Hou, J.; Qian, J. Preparation, characterization and photocatalytic activity of the neodymium-doped $\mathrm{TiO}_{2}$ hollow spheres. Appl. Surf. Sci. 2010, 257, 227-231. [CrossRef]

62. Khodadadi, B. Effects of $\mathrm{Ag}, \mathrm{Nd}$ codoping on structural, optical and photocatalytic properties of $\mathrm{TiO}_{2}$ nanocomposite synthesized via sol-gel method using starch as a green additive. Iran. J. Catal. 2016, 6, 305-311.

63. Beydoun, D.; Amal, R.; Low, G.; McEvoy, S. Role of Nanoparticles in Photocatalysis. J. Nanopart. Res. 1999, 1, 439-458. [CrossRef]

64. Nahar, M.S.; Hasegawa, K.; Kagaya, S. Photocatalytic degradation of phenol by visible light-responsive iron-doped TiO ${ }_{2}$ and spontaneous sedimentation of the $\mathrm{TiO}_{2}$ particles. Chemosphere 2006, 65, 1976-1982. [CrossRef]

65. Qian, R.; Zong, H.; Schneider, J.; Zhou, G.; Zhao, T.; Li, Y.; Yang, J.; Bahnemann, D.; Pan, J.H. Charge carrier trapping, recombination and transfer during $\mathrm{TiO}_{2}$ photocatalysis: An overview. Catal. Today 2019, 335, 78-90. [CrossRef]

66. Blaskov, V.; Ninova, I.; Znaidi, L.; Stambolova, I.; Michel, J.P.; Vassilev, S.; Beauverger, M.; Klissurski, D.; Kanaev, A. SEM characterization of spin-coated nanocrystalline $\mathrm{TiO}_{2}$ thin film influenced by the presence of acetylacetone during the sol preparation. In Nanoscience E Nanotechnology, 4th ed.; Balabanova, E., Dragieva, I., Eds.; Heron Press: Sofia, Bulgaria, 2004; Volume 4, pp. 191-193.

67. Sannino, F.; Pernice, P.; Imparato, C.; Aronne, A. Hybrid $\mathrm{TiO}_{2}$-Acetylacetonate Amorphous Gel-Derived Material with Stably Adsorbed Superoxide Radical Active in Oxidative Degradation of Organic Pollutants. RSC Adv. 2015, 5, 93831-93839. [CrossRef]

68. Valgas, C.; de Souza, S.M.; Smania, E.F.A., Jr. Screening methods to determine antibacterial activity of natural products. Braz. J. Microbiol. 2007, 38, 369-380. [CrossRef] 